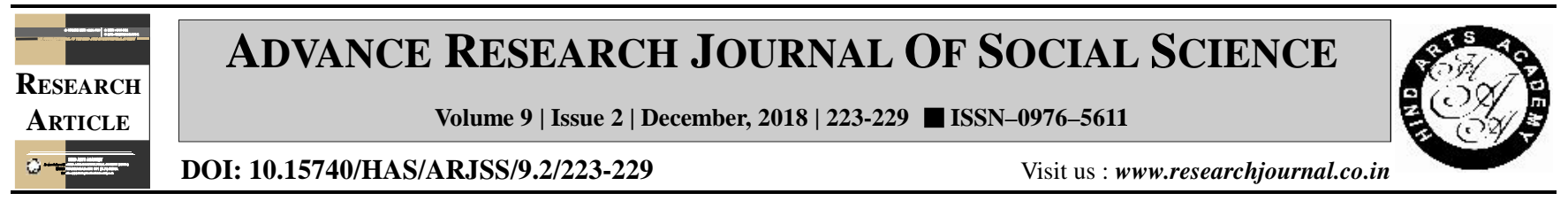

\title{
A study on identification of stimulation level for children at home environment
}

\author{
Ankita Dutta* and Vishakha Singh
}

Department of Human Development and Family Studies, College of Community Science, Assam Agricultural University, Jorhat (Assam) India

Email:duttaankita2017@gmail.com

\section{ARTICLE INFO :}

$\begin{array}{lll}\text { Received } & : & 04.10 .2018 \\ \text { Revised } & : & 17.11 .2018 \\ \text { Accepted } & : & 21.11 .2018\end{array}$

\section{KEY WORDS :}

Stimulation, Connections, Brain development, Home environment

HOW TO CITE THIS ARTICLE : Dutta, Ankita and Singh, Vishakha (2018). A study on identification of stimulation level for children at home environment. Adv. Res. J. Soc. Sci., 9 (2): 223-229, DOI: 10. 15740/HAS/ARJSS/ 9.2/223-229.Copyright@2018: Hind Agri -Horticultural Society

*Author for correspondence

\begin{abstract}
Stimulation is the action of various agents or stimuli on nerves, muscles, or a sensory end organ, by which activity is evoked. Stimulation helps a child to grow through newer experiences, which facilitates the brain to form numerous connections and hence, brain development takes place. Home environment is the immediate environment to which the child is exposed from the beginning of life. It should be stimulating so as to help a child to grow through newer experiences, which facilitates the brain to form numerous connections and hence brain development and overall development takes place. The present study was undertaken to know the level of stimulation provided to children at home environment. The sample size comprised of 60 mothers having school going (grades I-IV) children selected from Bakchung block of Jorhat subdivision. The Mohite Home Environment inventory was administered to collect the research data. An interview schedule was also prepared to collect background data. It was found that majority $(70 \%)$ of the households provided moderate level of stimulation at home environment while 21.66 per cent of the households provided high level of stimulation and only few of them (8.33\%) provided poor level of stimulation to children at home environment.
\end{abstract}

